Article

\title{
Spectrophotometric Evaluation of Polyetheretherketone (PEEK) as a Core Material and a Comparison with Gold Standard Core Materials
}

\author{
Bogna Stawarczyk ${ }^{1, *}$, Philipp Schmid ${ }^{2}$, Malgorzata Roos ${ }^{3}$, Marlis Eichberger ${ }^{1}$ and \\ Patrick R. Schmidlin ${ }^{2}$ \\ 1 Department of Prosthodontics, Dental School, Ludwig-Maximilians-University Munich, Goethestrasse 70, \\ Munich 80336, Germany; marlis.eichberger@med.uni-muenchen.de \\ 2 Clinic of Preventive Dentistry, Periodontology and Cariology, Center of Dental Medicine, \\ University of Zurich, Plattenstrasse 11, Zurich 8032, Switzerland; \\ philipp.schmid@swissdentalcenter.ch (P.S.); Patrick.Schmidlin@zzm.uzh.ch (P.R.S.) \\ 3 Division of Biostatistics, Epidemiology Biostatistics and Prevention Institute, University of Zurich, \\ Hirschengraben 84, Zurich 8001, Switzerland; mroos@ifspm.uzh.ch \\ * Correspondence: bogna.stawarczyk@med.uni-muenchen.de; Tel.: +49-89-4400-59573; Fax: +49-89-4400-59502 \\ Academic Editor: Marco Salerno \\ Received: 9 May 2016; Accepted: 16 June 2016; Published: 20 June 2016
}

\begin{abstract}
This study investigated the colorimetric properties of different veneering materials on core materials. Standardized specimens $(10 \mathrm{~mm} \times 10 \mathrm{~mm} \times 1.5 \mathrm{~mm})$ reflecting four core (polyetheretherketone (PEEK), zirconia $\left(\mathrm{ZrO}_{2}\right)$, cobalt-chromium-molybdenum alloy $(\mathrm{CoCrMo})$, and titanium oxide $\left(\mathrm{TiO}_{2}\right)$; thickness: $1.5 \mathrm{~mm}$ ) and veneering materials (VITA Mark II, IPS e.max CAD, LAVA Ultimate and VITA Enamic, all in shade A3; thickness: 0.5, 1.0, 1.5 and $2 \mathrm{~mm}$, respectively) were fabricated. Specimens were superimposed to assemblies, and the color was determined with a spectrophotometer (CieLab-System) or a chair-side color measurement device (VITA EasyShade), respectively. Data were analyzed using three-, two-, and one-way ANOVA, a Chi ${ }^{2}$-test, and a Wilson approach $(p<0.05)$. The measurements with EasyShade showed A2 for VITA Mark II, A3.5 for VITA Enamic, B2 for LAVA Ultimate, and B3 for IPS e.max CAD. LabE-values showed significant differences between the tested veneering materials $(p<0.001)$. CieLab-System and VITA EasyShade parameters of the different assemblies showed a significant impact of core $(p<0.001)$, veneering material $(p<0.001)$, and thickness of the veneering material $(p<0.001)$. PEEK as core material showed comparable outcomes as compared to $\mathrm{ZrO}_{2}$ and CoCrMo, with respect to CieLab-System parameters for each veneering material. The relative frequency of the measured VITA EasyShade parameters regarding PEEK cores also showed comparable results as compared to the gold standard CoCrMo, regardless of the veneering material used.
\end{abstract}

Keywords: polyetheretherketone (PEEK); color; spectrophotometer; chair-side color measurements

\section{Introduction}

Restoring and replacing teeth with computer-aided design and computer-aided manufacturing (CAD/CAM) [1] has gained in popularity and become a key competence in dentistry. However, oral rehabilitation is delicate in terms of functional and esthetic outcomes and only an adequate material choice and processing can ensure long-term stability and patient satisfaction on teeth and implants $[2,3]$. Whereas, at first sight, the esthetic appearance of any restoration is of great subjective importance for patient and oral care provider, other significant aspects like biocompatibility, function, and longevity play a substantial role [4]. 
Whereas veneering materials aim to rebuild the outer body of the tooth, abutment and core materials are required to reinforce the integrity and stability of the restoration [5]. However, the color of the latter may greatly influence the appearance of the whole restoration and may hamper adequate esthetics [6]. Therefore, besides physical-chemical testing, the materials ability to mimic the natural tooth substance with regard to translucency, opalescence, and overall color is also important when screening and evaluating potential restorative materials and combinations thereof [7].

Polyetheretherketone (PEEK) represents a relatively new material and is regarded as a promising alternative in fixed and removable prosthetic dentistry. It is a linear, aromatic, semi-crystalline thermoplastic polymer with notable mechanical properties [8]. Recent studies have shown that it fulfills the basic requirements to be used in the restorative field as it shows adequate mechanical stability and also allows for bonding to conventional veneering materials [9,10]. However, this material may significantly interfere with the aforementioned desired esthetic outcomes, as the clinical use of PEEK as full-coverage monolithic restorations may be notably limited by its low translucency and a grayish or even snow-white color. Therefore, additional resin composite or ceramic materials for veneering are still necessary, especially in the esthetic zone. To date, according to the authors' knowledge, no studies are available, which have investigated color characteristics and optical properties of PEEK as compared to other currently used abutment materials in combination with veneering materials.

Since spectrophotometric technologies (e.g., CieLab-System) are widely used in dental color studies [11], the present study was designed using this technology to assess differences in optical measurements of PEEK as a base material as compared to three frequently used base materials, namely, a metal alloy (so-called gold standard), zirconia, and titanium, when layered with four different veneering materials of different thicknesses. The following six null hypotheses were formulated:

(1) There is no difference in the CieLab-System parameters of assemblies and the modification of the CieLab-System parameters for each veneering material separately.

(2) The veneering materials have no impact on CieLab-System parameters.

(3) The core materials within given assemblies have no impact on the CieLab-System parameters.

(4) The core material has no impact on the modification of the CieLab-System parameters between assembly and veneering material.

(5) The veneering materials have no impact on the VITA EasyShade parameters.

(6) The core materials have no impact on the VITA EasyShade parameters.

\section{Materials and Methods}

\subsection{Specimen Preparation}

In order to test the variety of restorative combinations, different core and veneering materials were evaluated. For this purpose, ten test specimens reflecting four different core materials (PEEK, zirconia $\left(\mathrm{ZrO}_{2}\right)$, cobalt-chromium-molybdenum alloy (CoCrMo), and titanium oxide $\left.\left(\mathrm{TiO}_{2}\right)\right)$ were prepared in standardized dimensions of $10 \mathrm{~mm} \times 10 \mathrm{~mm} \times 1.5 \mathrm{~mm}$. The materials used in this study are presented in Table 1.

The respective $\mathrm{CAD} / \mathrm{CAM}$ materials, i.e., PEEK, $\mathrm{ZrO}_{2}$, and $\mathrm{TiO}$, as well as the residue-combustible acrylic VITA CAD-Wax (VITA Zahnfabrik, Lot. No: 22890) for the CoCrMo specimens, were cut into 2-mm-thick slices. $\mathrm{ZrO}_{2}$ specimens were sintered (LHT 02/16, Nabertherm $\mathrm{GmbH}$, Lilienthal/Bremen, Germany) according to the manufacturer instructions at a heating rate of $10^{\circ} \mathrm{C} / \mathrm{min}$ to $1500{ }^{\circ} \mathrm{C}$ with a holding time of $120 \mathrm{~min}$. The wax specimens were invested (TeleVest, Siladent, Goslar, Germany; Lot. No: 1304672/12289) and cast in an induction vacuum casting machine (GLOBUCAST, Obodent, Bohmte, Germany) according to the manufacturer's instructions using a CoCrMo alloy (Table 1). After cooling, the investment material was removed in an air-abrasion unit (CEMAT NT4, Wassermann, Hamburg, Germany) using $50 \mu \mathrm{m}$ of $\mathrm{Al}_{2} \mathrm{O}_{3}$ (Cobra, Renfert, Hilzinger, Germany) at a pressure of 2 bar. 
Table 1. Overview of the materials tested in this study.

\begin{tabular}{|c|c|c|c|c|}
\hline Brands & Material Type & Manufacturer & Batch No. & Composition \\
\hline \multicolumn{5}{|c|}{ Core Materials } \\
\hline Dentokeep & PEEK & $\begin{array}{l}\text { nt-trading, Karlsruhe, } \\
\text { Germany }\end{array}$ & 11DK14Q01 & $\begin{array}{l}\text { PEEK, } 20 \mathrm{wt} \% \\
\text { anorganic fillers }\end{array}$ \\
\hline IPS e.max ZirCAD & $\mathrm{ZrO}_{2}$ & $\begin{array}{l}\text { Ivoclar Vivadent, } \\
\text { Schaan, Liechtenstein }\end{array}$ & N35700 & $\begin{array}{l}\mathrm{ZrO}_{2}, \mathrm{HFO}_{2}, \mathrm{Al}_{2} \mathrm{O}_{3} \text { and } \\
\text { other oxides }\end{array}$ \\
\hline Remanium GM 800+ & CoCrMo & $\begin{array}{c}\text { Dentanium, Ispringen, } \\
\text { Germany }\end{array}$ & 816 & $\begin{array}{c}\text { Co } 63.3 \text { wt } \%, \\
\text { Cr } 30 \text { wt } \% \text {, Mo } 5 \text { wt } \% \\
\end{array}$ \\
\hline Bio-Titan & $\mathrm{TiO}_{2}$ & $\begin{array}{c}\text { DCS Dental AG, } \\
\text { Allschwil, Switzerland }\end{array}$ & 8797 & pure titanium grade 4 \\
\hline \multicolumn{5}{|c|}{ Veneering Materials } \\
\hline VITA Mark II A3 & glass-ceramic & $\begin{array}{l}\text { VITA Zahnfabrik, Bad } \\
\text { Säckingen, Germany }\end{array}$ & 29380 & $\begin{array}{c}\mathrm{SiO}_{2}: 56-64 \mathrm{wt} \%, \mathrm{Al}_{2} \mathrm{O}_{3}: \\
20-23 \mathrm{wt} \%, \mathrm{Na}_{2} \mathrm{O}: \\
\text { 6-9 wt \%, } \mathrm{K}_{2} \mathrm{O}: \\
6-8 \mathrm{wt} \%, \mathrm{CaO}: 0.3-0.6 \mathrm{wt} \%\end{array}$ \\
\hline IPS e.max CAD A3 & $\begin{array}{l}\text { lithium disilicate } \\
\text { glass-ceramic }\end{array}$ & $\begin{array}{l}\text { Ivoclar Vivadent, } \\
\text { Schaan, Liechtenstein }\end{array}$ & S14448 & $\begin{array}{c}\mathrm{SiO}_{2}, \mathrm{Li}_{2} \mathrm{O}, \mathrm{K}_{2} \mathrm{O}, \mathrm{MgO}, \\
\mathrm{Al}_{2} \mathrm{O}_{3}, \mathrm{P}_{2} \mathrm{O}_{5} \text { and other oxides }\end{array}$ \\
\hline LAVA Ultimate & resin nano ceramic & $\begin{array}{l}\text { 3M ESPE, Seefeld, } \\
\text { Germany }\end{array}$ & N435300 & $\begin{array}{c}\text { Polymer with appr. } \\
80 \mathrm{wt} \% \text { anorganic filler }\end{array}$ \\
\hline VITA Enamic & hybrid dental ceramic & $\begin{array}{l}\text { VITA Zahnfabrik, Bad } \\
\text { Säckingen, Germany }\end{array}$ & 36810 & $\begin{array}{c}86 \mathrm{wt} \% \text { feldspar ceramic, } \\
14 \text { wt } \% \text { polymer }\end{array}$ \\
\hline
\end{tabular}

In addition, the following CAD/CAM materials-all in A3 chairside color as delivered by the manufacturer-were chosen to simulate the veneering situation: VITA Mark II, IPS e.max CAD, LAVA Ultimate, and VITA Enamic (Table 1). Blanks were cut using a low-speed diamond saw (Well 3241, Well Diamantdrahtsägen, Mannheim, Germany) in accordance with standardized thicknesses of $0.5 \pm 0.01,1.0 \pm 0.01,1.5 \pm 0.01$, and $2 \pm 0.01 \mathrm{~mm}$, respectively. Thereafter, core and veneering materials were polished on both sides under constant water-cooling up to silicon carbide paper (SIC) P4000 (Tegramin-20, Struers, Ballerup, Denmark).

\subsection{Specimen Assembly and Color Determination}

In a first step, the color of the different core materials was determined according to the CieLab-System with a spectrophotometer (CM 3500d, Minolta AG, Dietikon, Switzerland). The measurement tip of the spectrophotometer was always directed towards the middle of the specimens, and the spectrophotometer recorded the $L$ (luminosity), $a$ (red-green axis), and $b$-values (yellow-blue axis). Additionally, $E$-values were calculated according to the formula: $E=\left[(L)^{2}+(a)^{2}+(b)^{2}\right]^{1 / 2}$. After the 10 measurements, the means of each material group were determined, and the sample best fitting to this mean value served as the master base material for the measurements to follow. Afterwards, the veneering materials of different thicknesses were superimposed individually, and the measurements were made in triplicates using the spectrophotometer at the veneering thicknesses of $0.5,1.0,1.5$, and $2.0 \mathrm{~mm}$.

The 2-mm-thick veneering specimens of each material specimen served as a control reference for the color measurements of the CieLab-System measurements for the difference determination $(\Delta L, \Delta a$, and $\Delta b$ ) between the different readings of the combined base/veneering material assemblies. The overall color difference was again calculated as $\Delta E=\left[(\Delta L)^{2}+(\Delta a)^{2}+(\Delta b)^{2}\right]^{1 / 2}$, where $\Delta L=L$ (veneering) $-L$ (assembly); $\Delta a=a$ (veneering) $-a$ (assembly); $\Delta b=b$ (veneering) $-b$ (assembly).

The following color definitions for the respective positive $(+)$ and negative $(-)$ values were used for all interpretations:

$$
\Delta L=(+) \text { white, }(-) \text { black; } \Delta b=(+) \text { yellow }(-) \text { blue; } \Delta a=(+) \text { red, }(-) \text { green }
$$

In addition to that, a chair-side color measurement device was used to determine the VITA EasyShade of each assembly (VITA EasyShade Compact, Vident, Model \# DEASYCBU, Serial Number 20365). Before each measurement, the device was calibrated using the calibration 
apparatus according to the manufacturer's instructions. The measurements were repeated three times and coded in an excel sheet.

\subsection{Statistical Evaluation}

Descriptive statistics such as mean and standard deviation were computed. The differences between the groups with respect to CieLab-System parameters and factors such as framework material, veneering material, and veneering material thickness as well as their interactions were determined using three-way ANOVA. The interaction between all factors affected the results. Therefore, the fixed effects of framework material, veneering material, and veneering thickness cannot be compared directly as the higher-order interactions were found to be significant. Consequently, several different analyses using two- and one-way were computed and divided by the level of framework material, veneering material, and veneering depending on the hypothesis of interest. The association between VITA EasyShade values (chair-side tooth shade) and veneering material as well as core material was investigated with a Chi ${ }^{2}$-test. In addition, the relative frequencies of VITA EasyShade values were given using the Wilson approach (SPSS V20, SPSS INC, Chicago, IL, USA). All results for statistical analyses with $p$-values below $p=0.05$ were considered to be statistically significant.

\section{Results}

\subsection{The Evaluation of the Color Properties of the Veneering Materials}

The chair side tooth shade was defined with A3 according to the manufacturer of all four veneering materials (Table 1). The measurements in this study showed that VITA Mark II is A2, VITA Enamic A3.5, LAVA Ultimate B2, and IPS e.max CAD B3 (Table 2).

Table 2. Descriptive statistics of the CieLab-System parameters (mean, standard deviation (SD) of veneering materials together with VITA EasyShade evaluations.

\begin{tabular}{|c|c|c|c|c|c|}
\hline \multirow{2}{*}{ VITA EasyShade } & \multirow{2}{*}{ Lab-Values } & VITA Mark II & VITA Enamic & LAVA Ultimate & IPS e.max CAD \\
\hline & & A2 & A3.5 & B2 & B3 \\
\hline \multirow{3}{*}{ CieLab-System } & $L$ mean $(\mathrm{SD})$ & $62.7(1.3)^{\mathrm{b}}$ & $60.4(1.3)^{\mathrm{a}}$ & $60.1(1.9)^{a}$ & $62.7(0.7)^{\mathrm{b}}$ \\
\hline & $b$ mean (SD) & $9.0(2.9)^{b}$ & $11.5(2.4)^{\mathrm{c}}$ & $2.4(2.3)^{\mathrm{a}}$ & $9.7(2.4)^{\mathrm{b}}$ \\
\hline & $E$ mean (SD) & $63.4(1.5)^{c}$ & $61.5(1.7)^{b}$ & $60.2(1.9)^{\mathrm{a}}$ & $63.6(0.9)^{b}$ \\
\hline
\end{tabular}

$\mathrm{a}, \mathrm{b}, \mathrm{c}, \mathrm{d}$ different letters show significant differences between tested veneering materials within one CieLab-System parameter.

The corresponding color space values (LabE) to the chair-side color are presented in Table 2. LabE-values showed significantly differences between the tested veneering materials $(p<0.001)$. With regard to lightness (L), VITA Mark II (A2) and IPS e.max CAD (B3) showed significantly higher values than VITA Enamic (A3.5) and LAVA Ultimate (B2) $(p<0.001)$. The lowest color opponents dimension was observed for LAVA Ultimate (B2), followed by IPS e.max CAD (B3), VITA Mark II (A2), and VITA Enamic (A3.5), respectively $(p<0.001)$. Among b-color values, VITA Enamic (A3.5) showed the highest b color opponents dimension, followed by VITA Mark II (A2) and LAVA Ultimate (B3). However, the latter were in the same range $(p=0.08)$. Within the global values $(E)$, the lowest $E$-values were observed for LAVA Ultimate (B2), followed by VITA Enamic (A3.5) $(p<0.001)$. The highest E-values showed VITA Mark II (A2) and IPS e.max CAD (B3), which were not significantly different from each other $(p=0.941)$ (Table 2$)$.

The CieLab-System parameters and VITA EasyShade parameters of the different assemblies between veneering and core material were evaluated.

The three-way ANOVA indicated that the core $(p<0.001)$ and veneering material $(p<0.001)$, and the thickness of the veneering material $(p<0.001)$ had a significant impact on the CieLab-System parameters. 
In general, $\mathrm{TiO}_{2}$ showed significantly lower $L$ - and $E$-value as compared to the other core materials $(p<0.001$; Figure 1). In contrast, with consideration of the $a$-value, PEEK resulted in significantly higher values than the other three core materials $(p<0.001)$. With regard to the $b$-value, PEEK showed again the highest results, followed by $\mathrm{ZrO}_{2}$ and $\mathrm{CoCr}$. The lowest $b$-values were observed for $\mathrm{TiO}_{2}$. These results were independent of the used veneering material.
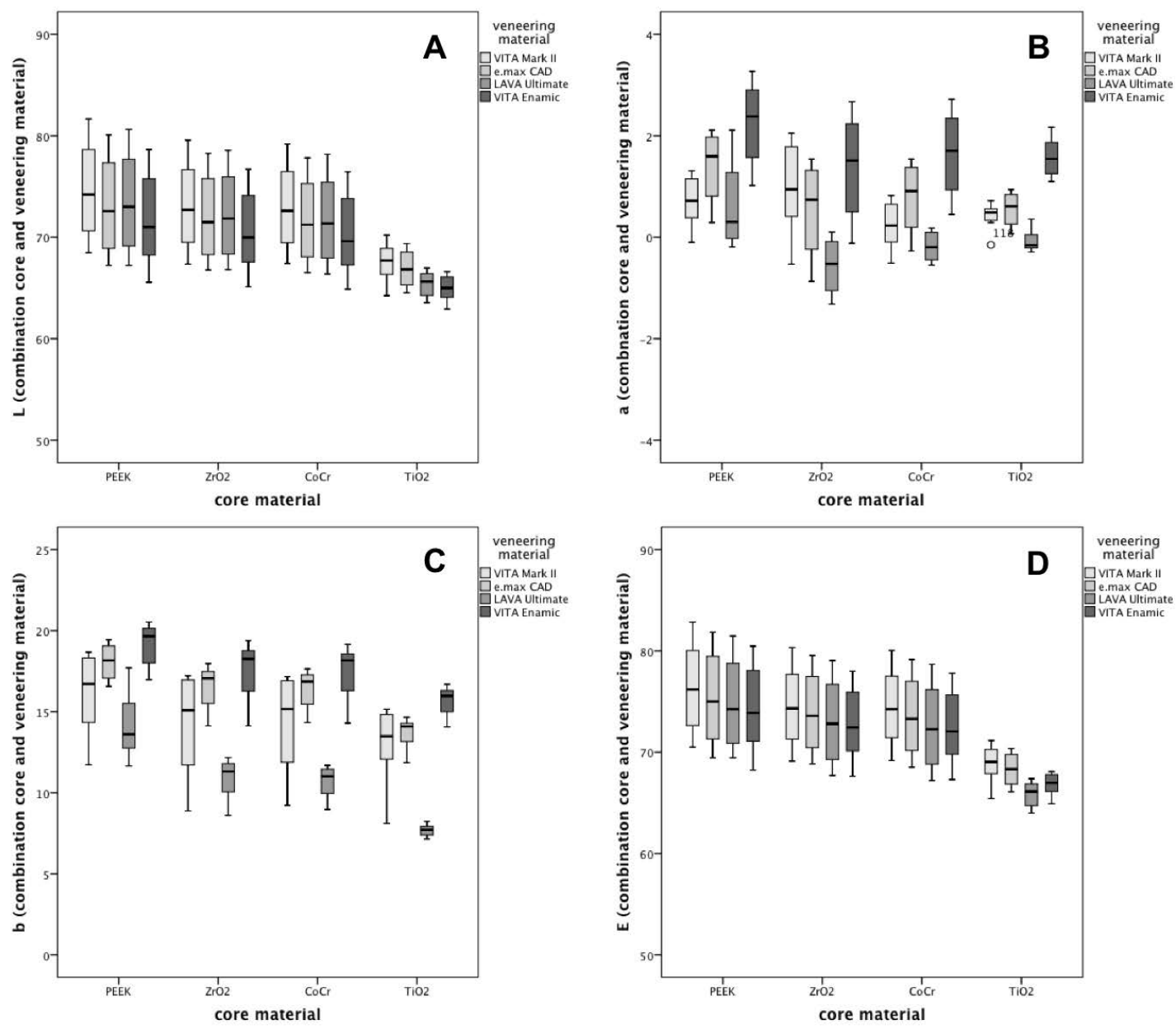

Figure 1. CieLab-System parameters of all tested material assemblies, regardless of the veneering thickness.

With regard to lightness $(L)$-values, VITA Enamic showed the lowest values followed by LAVA Ultimate, IPS e.max CAD and VITA Mark II, respectively $(p<0.001)$. Focusing on $a$ - and $b$-values, the same range and order was observed. Lava Ultimate presented the lowest values followed by VITA Mark II, IPS e.max CAD, and VITA Enamic. When considering the global $E$-value, VITA Enamic and LAVA Ultimate were in the same range, whereas IPS e.max CAD and VITA Mark II presented significantly higher $E$-values.

The measured VITA EasyShade parameters showed an impact of the core and veneering material combination $\left(\mathrm{Chi}^{2}: p<0.001\right)$. Core material in combination with VITA Mark II (A2) showed the following predominant tooth shades: A1 (39.4\%), A2 (36.3\%), respectively (Table 3). For VITA Enamic (A3.5) core, the predominant shades measured were B3 (53.8\%) and A3.5 (13.1\%). For LAVA Ultimate (B2), tooth shades A1 (36.9\%), B2 (31.9\%), and A2 (18.8\%) were predominant. In contrast, IPS e.max CAD (B3) showed mainly B3 (46.3\%) and B2 (20.6\%) values. Although all veneering materials were delivered from the manufacturers with $\mathrm{A} 3$, this tooth shade was only measured in $11.6 \%$ of all combinations in this study. 
Table 3. Relative frequency (\%) and $95 \%$ CI of the measured VITA EasyShade parameters of all assemblies between core and veneering material, regardless of the veneering thickness and core materials (left)/veneering materials (right).

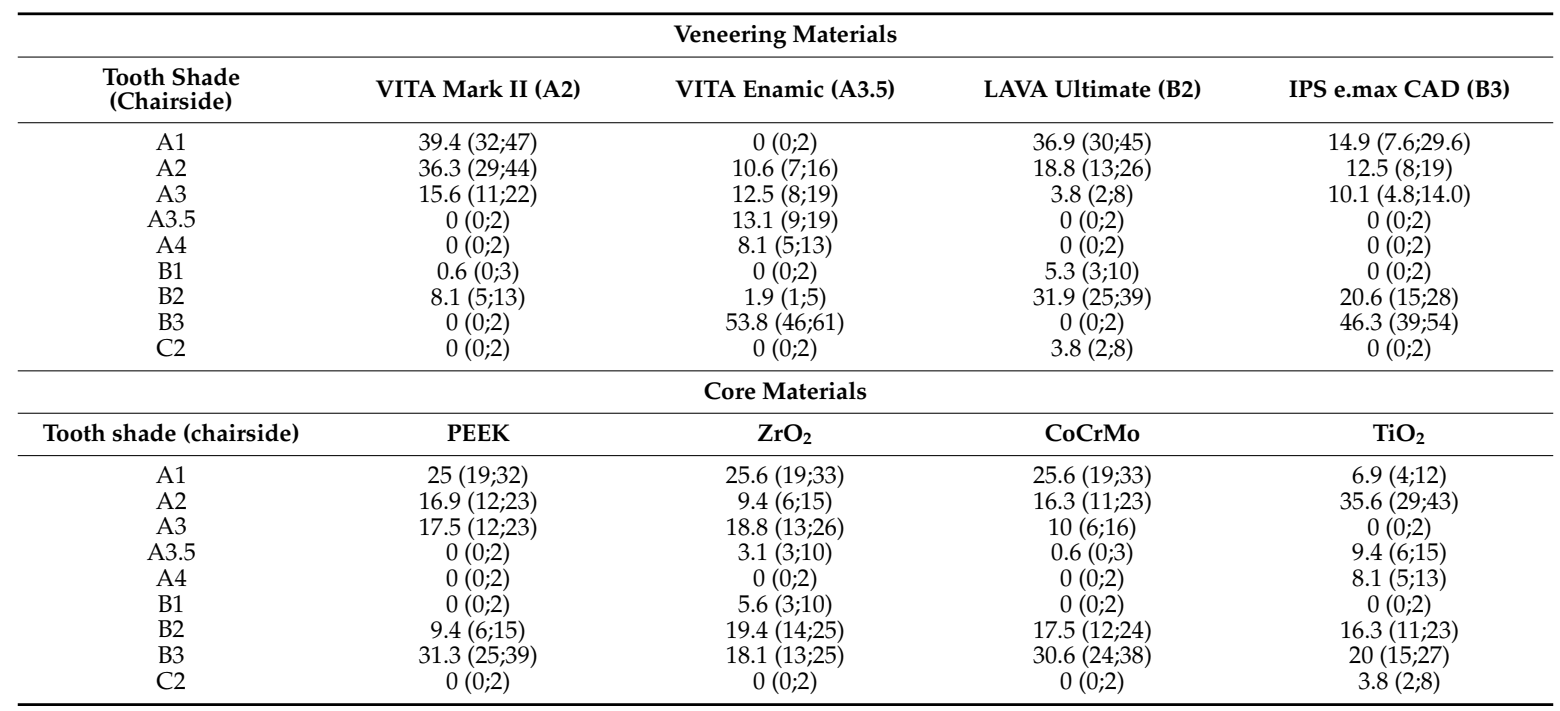

The relative frequency of the measured VITA EasyShade parameters for PEEK core material (A1: 25\%, A2: 17\%, B3: 31\%) showed comparable results with CoCrMo (A1: 25\%, A2: 16\%, B3: 31\%), regardless of the veneering material used.

\subsection{Influencing the Overall CieLab-System Parameters through the Core Material}

The three-way ANOVA indicated that core $(p<0.001)$ and veneering material $(p<0.001)$ as well as of the thickness of the veneering material $(p<0.001)$ had a significant impact on values $\Delta L, \Delta a$, $\Delta b$ and $\Delta E$. In general, the lightness parameter $\Delta L$ produced significantly higher values for $\mathrm{TiO}_{2}$ as compared with the other core materials, regardless of the veneering material $(p<0.001$; Table 4$)$. For veneering materials VITA Enamic, LAVA Ultimate, and IPS e.max CAD, comparable influences of the core material were shown, i.e., the lowest $\triangle a$-values were recorded in groups combined with PEEK core and then with $\mathrm{CoCrMo}$ and $\mathrm{TiO}_{2}(p<0.001)$. However, the highest $\Delta a$-values were shown in combination with $\mathrm{ZrO}_{2}(p<0.001)$. Within groups veneering with VITA Mark II, the combination with $\mathrm{ZrO}_{2}$ showed the lowest $\triangle a$-values, followed by $\mathrm{PEEK}$ and $\mathrm{TiO}_{2}$ as well as $\mathrm{CoCrMo}$, respectively $(p<0.001)$. For $\Delta b$ results, the combination with the core material PEEK revealed the lowest values, followed by $\mathrm{ZrO}_{2}, \mathrm{CoCrMo}$, and $\mathrm{TiO}_{2}(p<0.001)$, regardless of the veneering material. $\Delta E$-values revealed a significant influence of the core material regardless of the veneering material $(p<0.001)$ in the following decreasing order: $\mathrm{TiO}_{2}, \mathrm{CoCrMo}, \mathrm{ZrO}_{2}$, and PEEK.

Table 4. Descriptive statistics of modifications of the CieLab-System parameters (baseline: veneering material) of all tested material assemblies, regardless of the veneering thickness.

\begin{tabular}{|c|c|c|c|c|c|}
\hline VITA EasyShade & Lab-Values & VITA Mark II/A2 & VITA Enamic/A3.5 & LAVA Ultimate/B2 & IPS e.max CAD/B3 \\
\hline \multicolumn{6}{|c|}{ PEEK } \\
\hline CieLab-System & $\begin{array}{l}\Delta L \text { mean }(\mathrm{SD}) \\
\Delta a \text { mean }(\mathrm{SD}) \\
\Delta b \text { mean }(\mathrm{SD}) \\
\Delta E \text { mean }(\mathrm{SD})\end{array}$ & $\begin{array}{l}-12.1(5.2) \\
-0.8(0.3) \\
-7.4(1.8) \\
14.3(5.1)\end{array}$ & $\begin{array}{l}-11.2(5.9) \\
-1.4(0.1) \\
-7.6(1.6) \\
13.8(5.8)\end{array}$ & $\begin{array}{c}-13.4(6.6) \\
-2.3(0.5) \\
-11.7(1.5) \\
18.4(5.4)\end{array}$ & $\begin{array}{l}-10.3(5.2) \\
-1.9(0.1) \\
-8.4(2.1) \\
13.6(5.3)\end{array}$ \\
\hline \multicolumn{6}{|c|}{$\mathrm{ZrO}_{2}$} \\
\hline
\end{tabular}


Table 4. Cont.

\begin{tabular}{|c|c|c|c|c|c|}
\hline VITA EasyShade & Lab-Values & VITA Mark II/A2 & VITA Enamic/A3.5 & LAVA Ultimate/B2 & IPS e.max CAD/B3 \\
\hline \multicolumn{6}{|c|}{ CoCrMo } \\
\hline CieLab-System & $\begin{array}{l}\Delta L \text { mean }(\mathrm{SD}) \\
\Delta a \text { mean }(\mathrm{SD}) \\
\Delta b \text { mean }(\mathrm{SD}) \\
\Delta E \text { mean }(\mathrm{SD})\end{array}$ & $\begin{array}{l}-10.4(4.7) \\
-0.3(0.3) \\
-5.5(1.6) \\
11.9(4.5)\end{array}$ & $\begin{array}{l}-9.8(5.4) \\
-0.8(0.1) \\
-5.9(1.1) \\
11.6(5.1)\end{array}$ & $\begin{array}{l}-11.7(6.1) \\
-1.4(0.1) \\
-8.3(1.8) \\
14.5(6.0)\end{array}$ & $\begin{array}{l}-8.9(4.6) \\
-1.3(0.1) \\
-6.7(1.6) \\
11.3(4.6)\end{array}$ \\
\hline \multicolumn{6}{|c|}{$\mathrm{TiO}_{2}$} \\
\hline
\end{tabular}

\section{Discussion}

The research interest in color measurement of teeth and dental restorations using different devices is increasing, especially when it comes to new materials. This includes different validation and comparative aspects, and the determination of thresholds and color interactions of human teeth and dental materials [12]. This is, to the best of our knowledge, the first study that assesses the influence of PEEK as a core material. PEEK is frequently the focus of oral rehabilitation studies, since PEEK-based materials are applied in addition to other polymers like poly(methyl methacrylate) (PMMA)-based and composite resin materials in removable and fixed partial denture technology. PEEK has become an alternative to conventional and well-investigated veneering and denture base resin materials, with low discoloration rates and improved mechanical properties [13-15].

Based on the results obtained, the hypotheses set as the premises of this study had to be rejected. In summary, the present study showed that the EasyShade method was not able to detect the delivered shade of A3 (A2 for VITA Mark II, A3.5 for VITA Enamic, B2 for LAVA Ultimate, and B3 for IPS e.max CAD). Accordingly, LabE-values also showed significant differences between the tested veneering materials of the same color $(p<0.001)$. Previous findings showed poor pair-agreement rates of shade matching instruments among the tested instruments (including the VITA EasyShade) ranging from $37.7 \%$ to $48.2 \%$, and the incidence of identical shade results shared by all instruments under investigation was only 25.9\% [16]. Different CieLab-System values and shade matching results were reported for identical teeth; therefore, a combination of shade matching instruments and visual shade confirmation was recommended for clinical use. In general, dental spectrophotometers rarely exhibit comparable shade selection outputs [16,17].

In the present study, however, both measurement methods, i.e., the VITA EasyShade and the CieLab-System, showed that the core $(p<0.001)$ and veneering material $(p<0.001)$, as well as the thickness of the veneering material $(p<0.001)$ of different assemblies, have a significant impact, which elucidates an inherent color difference in the different assemblies. These findings are not surprising, as it has been shown that especially metal substructures and different porcelains affect the final color of restorations [18]. Moreover, the porcelain thickness has been found to have an impact on chroma $[19,20]$.

The overall appearance and perception of dental restorations depends, however, on several factors: the color of the adjacent teeth, light scattering effects, and inherent material characteristics such as opacity and translucency. Detectable color differences to the human eye are normally non-discernible below $\Delta E$-values of 1 , which change into an unacceptable color set at $\Delta E$ when more than 3.3 [21-23]. In this light, the obtained values may be of clinical significance.

As a first general shortcoming of the present investigation, it must be pointed out that the base and veneering specimens were not superimposed with adhesion, i.e., no melting fusion or bonding/luting procedures were performed. This leaves the possibility of light scattering between the different samples. Another potentially critical factor in the methodology is that the specimens were polished, mainly aiming to reduce any additional scattering effects. However, this does not represent the realistic surface characteristics of routinely machined and milled specimens when using CAD/CAM devices. 
Finally, neither opaque luting materials nor colored cements were used, which has been shown to positively influence the optical behavior of CAD/CAM glass-ceramic lithium disilicate-reinforced restorations [24]. Therefore, our results should be interpreted with caution as the set-up probably led to more accentuated color differences. In favor of the present set-up, however, one may argue that it may be regarded as a worst-case scenario, depicting differences in core and veneering materials for screening purposes of a new core material, i.e., PEEK.

In the present study, four different restorative materials were used. They represent frequently used ceramic and polymer materials in CAD/CAM technology. In general, some variation in terms of translucent and fluorescent properties when compared with glass-ceramics of the same color was found [25]. In addition, it was shown that full-ceramic systems rarely match the color of the shade guide, which was also corroborated by the present study [26]. Specimens made from semi-translucent all-ceramic systems exhibited clinical shade matches that were superior to those made with the metal ceramic systems. Increasing thickness of the semi-translucent systems from 1.0 to $2.0 \mathrm{~mm}$ did not improve shade matching [27].

\section{Conclusions}

Within the limitations of the present study, the following conclusions can be drawn:

- PEEK as core material showed no differing tendencies when compared to gold standard core materials such as $\mathrm{ZrO}_{2}$ and CoCrMo with respect to the CieLab-System parameters of the assemblies and the modification of the CieLab-System parameters for each individual veneering material.

- Different veneering materials showed different CieLab-System and VITA EasyShade outcomes.

- The relative frequency of the measured VITA EasyShade parameters of PEEK cores showed comparable results with the gold standard $\mathrm{CoCrMo}$, regardless of the veneering material used.

- Core materials and the modification between assembly and veneering material showed significant impact on the CieLab-System and VITA Easy Shade results, i.e., the combination of core and veneering material was influential.

- Veneering materials influenced the VITA EasyShade parameters of the combination from core and veneering.

Acknowledgments: The authors would like to thank all manufacturers for supporting with materials.

Author Contributions: Bogna Stawarczyk is responsible for the idea, experimental design, data analyses, and manuscript writing. Philipp Schmid fabricated and measured the specimens; Malgorzata Roos performed the statistical analyses and proofread the manuscript; Marlis Eichberger supported and fabricated the specimen; Patrick R. Schmidlin is responsible for the idea, experimental design and manuscript writing.

Conflicts of Interest: The authors declare that they have no conflict of interest.

\section{Abbreviations}

The following abbreviations are used in this manuscript:

\begin{tabular}{|c|c|}
\hline $\mathrm{ZrO}_{2}$ & zirconia \\
\hline $\mathrm{TiO}_{2}$ & titanium oxide \\
\hline CoCrMo & cobalt-chromium-molybdenum alloy \\
\hline CAD/CAM & $\begin{array}{l}\text { computer-aided design/computer-aided } \\
\text { manufacturing }\end{array}$ \\
\hline
\end{tabular}

\section{References}

1. Batson, E.R.; Cooper, L.F.; Duqum, I.; Mendonca, G. Clinical outcomes of three different crown systems with CAD/CAM technology. J. Prosthet. Dent. 2014, 112, 770-777. [CrossRef] [PubMed] 
2. Pjetursson, B.E.; Asgeirsson, A.G.; Zwahlen, M.; Sailer, I. Improvements in implant dentistry over the last decade: Comparison of survival and complication rates in older and newer publications. Int. J. Oral Maxillofac. Implants 2014, 29, 308-324. [CrossRef] [PubMed]

3. Kopperud, S.E.; Tveit, A.B.; Gaarden, T.; Sandvik, L.; Espelid, I. Longevity of posterior dental restorations and reasons for failure. Eur. J. Oral Sci. 2012, 120, 539-548. [CrossRef] [PubMed]

4. Dietschi, D. Optimizing smile composition and esthetics with resin composites and other conservative esthetic procedures. Eur. J. Esthet. Dent. 2008, 3, 14-29. [PubMed]

5. Guess, P.C.; Att, W.; Strub, J.R. Zirconia in fixed implant prosthodontics. Clin. Implant. Dent. Relat. Res. 2012, 14, 633-645. [CrossRef] [PubMed]

6. Sinmazisik, G.; Demirbas, B.; Tarcin, B. Influence of dentin and core porcelain thickness on the color of fully sintered zirconia ceramic restorations. J. Prosthet. Dent. 2014, 111, 142-149. [CrossRef] [PubMed]

7. Villarroel, M.; Fahl, N.; De Sousa, A.M.; De Oliveira, O.B., Jr. Direct esthetic restorations based on translucency and opacity of composite resins. J. Esthet. Rest. Dent. 2011, 23, 73-87. [CrossRef] [PubMed]

8. Stawarczyk, B.; Beuer, F.; Wimmer, T.; Jahn, D.; Sener, B.; Roos, M.; Schmidlin, P.R. Polyetheretherketone-a suitable material for fixed dental prostheses? J. Biomed. Mater. Res. Part B Appl. Biomater. 2013, 101, 1209-1216. [CrossRef] [PubMed]

9. Stawarczyk, B.; Jordan, P.; Schmidlin, P.R.; Roos, M.; Eichberger, M.; Gernet, W.; Keul, C. PEEK surface treatment effects on tensile bond strength to veneering resins. J. Prosthet. Dent. 2014, 112, 1278-1288. [CrossRef] [PubMed]

10. Uhrenbacher, J.; Schmidlin, P.R.; Keul, C.; Eichberger, M.; Roos, M.; Gernet, W.; Stawarczyk, B. The effect of surface modification on the retention strength of polyetheretherketone crowns adhesively bonded to dentin abutments. J. Prosthet. Dent. 2014, 112, 1489-1497. [CrossRef] [PubMed]

11. Fairchild, M.D. Color appearance models and complex visual stimuli. J. Dent. 2010, 38, e25-e33. [CrossRef] [PubMed]

12. Chu, S.J.; Trushkowsky, R.D.; Paravina, R.D. Dental color matching instruments and systems. Review of clinical and research aspects. J. Dent. 2010, 38, e2-e16. [CrossRef] [PubMed]

13. Najeeb, S.; Zafar, M.S.; Khurshid, Z.; Siddiqui, F. Applications of polyetheretherketone (PEEK) in oral implantology and prosthodontics. J. Prosthodont. Res. 2016, 60, 12-19. [CrossRef] [PubMed]

14. Ayaz, E.A.; Durkan, R.; Koroglu, A.; Bagis, B. Comparative effect of different polymerization techniques on residual monomer and hardness properties of PMMA-based denture resins. J. Appl. Biomater. Funct. Mater. 2014, 30, 228-233. [CrossRef] [PubMed]

15. Kumari, R.V.; Nagaraj, H.; Siddaraju, K.; Poluri, R.K. Evaluation of the Effect of Surface Polishing, Oral Beverages and Food Colorants on Color Stability and Surface Roughness of Nanocomposite Resins. J. Int. Oral Health 2015, 7, 63-70. [PubMed]

16. Yuan, K.; Sun, X.; Wang, F.; Chen, J.H. In vitro and in vivo evaluations of three computer-aided shade matching instruments. Oper. Dent. 2012, 37, 219-227. [CrossRef] [PubMed]

17. Khashayar, G.; Dozic, A.; Kleverlaan, C.J.; Feilzer, A.J. Data comparison between two dental spectrophotometers. Oper. Dent. 2012, 37, 12-20. [CrossRef] [PubMed]

18. Kourtis, S.G.; Tripodakis, A.P.; Doukoudakis, A.A. Spectrophotometric evaluation of the optical influence of different metal alloys and porcelains in the metal-ceramic complex. J. Prosthet. Dent. 2004, 92, 477-485. [CrossRef] [PubMed]

19. Jarad, F.D.; Moss, B.W.; Youngson, C.C.; Russell, M.D. The effect of enamel porcelain thickness on color and the ability of a shade guide to prescribe chroma. Dent. Mater. 2007, 23, 454-460. [CrossRef] [PubMed]

20. Niu, E.; Agustin, M.; Douglas, R.D. Color match of machinable lithium disilicate ceramics: Effects of foundation restoration. J. Prosthet. Dent. 2013, 110, 501-509. [CrossRef] [PubMed]

21. Kuehni, R. Marcus M An experiment in visual scaling of small color differences. Color 1979, 4, 83-91.

22. Ruyter, I.E.; Nilner, K.; Moller, B. Color stability of dental composite resin materials for crown and bridge veneers. Dent. Mater. 1987, 3, 246-251. [CrossRef]

23. Um, C.M.; Ruyter, I.E. Staining of resin-based veneering materials with coffee and tea. Quintessence Int. 1991, 22, 377-386. [PubMed]

24. Chaiyabutr, Y.; Kois, J.C.; Lebeau, D.; Nunokawa, G. Effect of abutment tooth color, cement color, and ceramic thickness on the resulting optical color of a CAD/CAM glass-ceramic lithium disilicate-reinforced crown. J. Prosthet. Dent. 2011, 105, 83-90. [CrossRef] 
25. Guth, J.F.; Zuch, T.; Zwinge, S.; Engels, J.; Stimmelmayr, M.; Edelhoff, D. Optical properties of manually and CAD/CAM-fabricated polymers. Dent. Mater. J. 2013, 32, 865-871. [CrossRef] [PubMed]

26. Bagis, B.; Turgut, S. Optical properties of current ceramics systems for laminate veneers. J. Dent. 2013, 41, e24-e30. [CrossRef] [PubMed]

27. Douglas, R.D.; Przybylska, M. Predicting porcelain thickness required for dental shade matches. J. Prosthet. Dent. 1999, 82, 143-149. [CrossRef]

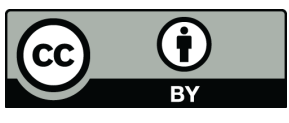

(C) 2016 by the authors; licensee MDPI, Basel, Switzerland. This article is an open access article distributed under the terms and conditions of the Creative Commons Attribution (CC-BY) license (http://creativecommons.org/licenses/by/4.0/). 